\title{
1. Introduction to the Research Handbook of Innovation for a Circular Economy
}

Siri Jakobsen, Thomas Lauvås, Francesco Quatraro, Einar Rasmussen and Marianne Steinmo

If it can't be reduced, reused, repaired, rebuilt, refurbished, refinished, resold, recycled, or composted, then it should be restricted, redesigned or removed from production.

\section{INTRODUCTION: THE URGENT NEED FOR A CIRCULAR ECONOMY}

The above lyric by the American folk singer and social activist Peter Seeger captures the essence of the circular economy (CE). By keeping materials in use, we can reduce the extensive resource extraction and depletion, and the related generation of waste and emissions that are threatening to kill our planet.

At the end of 2020 the weight of human-made objects was estimated to surpass the weight of all plants and animals on the planet (Elhacham et al. 2020). For every person on earth, new materials exceeding his or her bodyweight are produced every week. While the biomass on earth is declining due to deforestation and land-use changes, the amount of human-made objects are expected to double over the next 20 years (Elhacham et al. 2020).

This excessive extraction and use of resources and materials in the current linear economic model is draining the earth's resources and generating waste that pollutes and disturbs natural ecosystems at a rate that is severely damaging the living conditions on our planet. Only 25 per cent of earth's ice-free land can be considered as wilderness, and the population sizes of wildlife (mammals, birds, fish, amphibians and reptiles) have dropped by more than two-thirds since 1970 (Almond et al. 2020). A telling example is the prediction that there will be more plastic waste than fish in the world's oceans by 2050 (Ellen MacArthur Foundation 2017). Humans and livestock now constitute nearly all mammals on earth, only 4 per cent are wild animals and only 30 per cent of birds are wild ones (Bar-On et al. 2018). A growing number of ecosystems are at risk of collapsing, and global warming caused by greenhouse gas emissions is further destabilizing the earth system (Steffen et al. 2015).

It is clear that the constantly growing use of new raw materials and energy has severe consequences and cannot be sustained (Esposito et al. 2018). Paradoxically, most of the materials and resources that are extracted in the current linear 'make-use-dispose' economy quickly end up as waste and emissions, putting a double burden on the living conditions on our planet. Keeping materials and resources in use has the potential of both reducing the extraction of new raw materials and reducing the waste and emissions from discharging used material. Hence, making a transition to a CE that operates with closed material loops may be part of the solution to create a sustainable future (Stahel 2016). 
The basic idea of moving from a linear 'make-use-dispose' economic model to a circular one has gained a strong foothold among the public, policy makers, industry leaders and academics (Domenech and Bahn-Walkowiak 2019). Keeping materials and products at their highest utility and value at all times makes sense both from an environmental and a business perspective, and there are many examples of new circular business models that potentially can make the economy more circular (Esposito et al. 2018). Despite this growing interest in the $\mathrm{CE}$, the problems of resource extraction, waste and pollution are growing, and the global economy is currently getting less circular (De Wit et al. 2020).

\section{CIRCULAR ECONOMY AND THE NEED FOR INNOVATION}

Research on the CE is growing rapidly and the conceptual thinking behind circular resource flows in the economy is well established (Murray et al. 2017; Geissdoerfer et al. 2017; Sauvé et al. 2016). Much is written about the need for systemic changes to develop value chains that preserve materials and resources at their highest possible utility and value (Manninen et al. 2018), and potential strategies for achieving this. For instance, the extensively used ReSOLVE framework, proposed by the Ellen MacArthur Foundation (2015), defines six business actions for increasing the circularity of the economy: Regenerate, Share, Optimise, Loop, Virtualise, and Exchange (see Table 1.1).

The concept of circular business models has also gained popularity as a way to implement circularity at organizational level (Geissdoerfer et al. 2020; Henry et al. 2020). Circular business models can be defined as "business models that are cycling, extending, intensifying, and/ or dematerialising material and energy loops to reduce the resource inputs into and the waste and emission leakage out of an organizational system. This comprises recycling measures (cycling), use phase extensions (extending), a more intense use phase (intensifying), and the substitution of products by service and software solutions (dematerialising)" (Geissdoerfer et al. 2020).

\section{Table 1.1 The ReSOLVE framework}

\begin{tabular}{ll}
\hline ReSOLVE business actions & Description \\
\hline Regenerate & $\begin{array}{l}\text { Shift to renewable energy and materials; reclaim, retain, and regenerate health of ecosystems; and } \\
\text { return recovered biological resources to the biosphere }\end{array}$ \\
Keep product loop speed low and maximise utilisation of products by sharing them among users \\
(peer-to-peer sharing of privately owned products or public sharing of a pool of products), reusing \\
them throughout their technical lifetime (second-hand), and prolonging their life through maintenance, \\
repair, and design for durability \\
Increase performance/efficiency of a product; remove waste in production and the supply chain (from \\
sourcing and logistics to production, use, and end-of-use collection); leverage big data, automation, \\
remote sensing, and steering \\
Keep components and materials in closed loops and prioritise inner loops. For finite materials, this \\
means remanufacturing products or components and as a last resort recycling materials \\
Deliver utility virtually - books or music, online shopping, fleets of autonomous vehicles, and virtual \\
offices \\
Reoplace old materials with advanced non-renewable materials; apply new technologies (e.g., 3D \\
printing and electric engines); choose new products and services (e.g. multi-modal transport)
\end{tabular}

Source: Adapted from Ellen MacArthur Foundation (2015). 
Hence, the technical and operational aspects of the CE are relatively well described, and many studies offer practical approaches, providing tools and methods for modelling circular processes (Merli et al. 2018). Indeed, the literature review by Merli et al. (2018) shows that $\mathrm{CE}$ research predominantly considers cleaner production practices, while "little consideration is assigned to the design of new products and services, sharing and performance economy and dematerialization practices" (p. 717). Hence, there is a lack of knowledge about the institutional and societal transformations needed to implement circular practices (Moreau et al. 2017), particularly those requiring radical changes at societal and institutional level (Merli et al. 2018).

Indeed, making the transition to a more $\mathrm{CE}$ is very demanding because it requires substantial rethinking of the functioning of socio-economic systems. Hence, there is increasing consensus that full implementation of a CE requires a paradigm shift, involving new approaches to regulation and institutions, cultural and behavioural changes, and organizational, process and product innovation (Prieto-Sandoval et al. 2018). Moving from linear to circular resource flows influences and reshapes the design, production, distribution, consumption, and handling of products and materials in all sectors. In essence, the transition to a more CE requires innovation across all levels and actors in the society, i.e., firms, industries, individuals and institutions.

Innovation broadly refers to the process of generating new ideas or new combinations that are put into commercial practice in the form of new products, services or processes. Hence, there is an urgent need for a more comprehensive understanding of how such CE innovations can be achieved. This aligns well with the field of innovation studies, defined by Fagerberg et al. (2012, p. 1132) as "the scholarly study of how innovation takes place and what the important explanatory factors and economic and social consequences are". Despite the important role of innovation for implementing a more $\mathrm{CE}$, the term $\mathrm{CE}$ is relatively absent from the innovation literature. We searched the Scopus database early 2021 for the term 'circular economy' in some of the leading innovation journals and found a very limited number of hits (i.e., three in Research Policy, none in Technovation, none in Journal of Product Innovation Management, and none in Industrial and Corporate Change).

Hence, we believe there is an untapped potential in applying insights from the innovation literature to provide more specific implications for how to implement the transition from a linear to a CE. Similarly, the CE transition is an excellent context to study innovation processes and their outcomes. Overall, innovation is not only crucial for designing and implementing CE practices, but also an outcome facilitated by the increasing public and private initiatives to promote $\mathrm{CE}$ practices. This provides innovative firms with new business opportunities and favours the renewal of the existing ones.

\section{CHARACTERISTICS OF INNOVATIONS FOR A CIRCULAR ECONOMY}

The close interplay between the CE transition and innovation discussed above calls for a closer look at the innovation literature. In particular, the environmental benefits associated with the implementation of the CE model make innovations in this domain fall in the realm of what is known in the literature as eco-innovation, i.e., "the production, assimilation or exploitation of a product, production process, service or management or business methods that is novel to 
the firm [or organization] and which results, throughout its life cycle, in a reduction of environmental risk, pollution and other negative impacts of resources use (including energy use) compared to relevant alternatives" (Kemp and Pearson 2007, p. 7).

Accordingly, the tools and concepts developed in the field of economics of knowledge and innovation can be extended and further specified to analyse CE-oriented innovation. First of all, the Schumpeterian framework would suggest distinguishing between product, process and organisational innovation. Other relevant dimensions are the opening of new markets and the switch to new raw materials or providers (Schumpeter 1934).

Similarly, another important argument concerns the Schumpeterian definition of any kind of innovation as a combination of elements that have never been combined before. This intuition has paved the way to an approach to analysing the production of new knowledge, which is known as the recombinant-knowledge approach (Weitzmann 1998; Fleming and Sorenson 2001). Empirical and theoretical studies in this stream of literature propose that new knowledge emerges out of a recombinant process in which economic agents explore the technological landscape and try new combinations of existing pieces of knowledge to produce novelty (Saviotti 2007; Krafft et al. 2011). Cognitive aspects are crucial in this respect, with relatedness amongst technological domains an important factor affecting the likelihood of success of recombinant dynamics (Nightingale 1998).

The extension of this stream of literature to the analysis of the production of green knowledge has revealed that in the green domain the production of new knowledge on average rests on the combination of inputs pertaining to loosely related technological domains, i.e., on knowledge components that had never been combined together before, or that had been connected in a very limited number of cases. Green technologies are therefore considered as the outcome of pure recombinant creation efforts, rather than reuse. To put it differently, the introduction of new green technologies is strictly dependent on the capacity to command recombinant novelty (Zeppini and van den Bergh 2011).

Basic explanations of this evidence are grounded in the high degree of complexity of green knowledge (Barbieri et al. 2020), and in the observation that often the greening of economic activities requires hybridization of new green technologies with extant non-green ones. The same argument applies to the subset of CE-related technologies, which very often are developed out of combination of different and seemingly unrelated domains. A typical example is the production and utilization of bio-based materials, like bioplastics, which leads to the hybridization of value chains that had been unconnected before.

The emphasis on the importance of recombinant novelty and technological discontinuities has some important implications for the governance of CE-related knowledge production and its commercial exploitation. Increasing complexity of green technologies and the relevance of recombinant creation dynamics call for the establishment of collaborative dynamics to gain access to fragmented and dispersed knowledge. A large body of evidence has been put forward in this respect by extant literature (De Marchi 2012). The concept of open eco-innovation is increasingly used to stress that access to external sources of knowledge might be crucial for compensating the lack or insufficient development of the necessary capabilities to deal with the combination of knowledge components dispersed in the knowledge space (Ghisetti et al. 2015). Collective invention dynamics are expected to be even more important in the domain of CE-related innovation, in which interactions amongst a variety of different institutional actors are crucial to ensure the successful development of innovative solutions. Accordingly, 
the open CE-innovation is strictly intertwined with the discourse on the composition of CE-innovation ecosystems.

An institutional dimension that has been largely discussed by the eco-innovation literature concerns public intervention and regulation. These aspects are expected to play a crucial role in the CE transition. According to Rennings (2000), eco-innovation is subject to the well-known 'double externality' problem, according to which green knowledge is affected not only by the traditional source of externalities related to the public good characteristics of knowledge, but also by an additional source related to the reduction of environmental degradation. Accordingly, markets will fail in allocating the socially desirable amount of resources to the generation of green knowledge. For this reason, policy intervention is required to restore optimal levels of investments. Public policies can be designed according to the regulatory push-pull framework (Rennings, 2000). In this framework, a variety of policy measures can be leveraged, on the one hand to restore the economic incentives to invest in eco-innovations, and on the other hand to advance the frontier of knowledge in this domain to cope with new needs and challenges (Crespi et al. 2015). Besides these aspects, green public procurement represents an important tool to foster the transition to a $\mathrm{CE}$, both in view of the possibility to adopt circular solutions in the public administration, and as a way to orient the direction of research efforts.

\section{OUTLINE OF THE CONTRIBUTIONS IN THE HANDBOOK}

Given our objective of this handbook to explore the connections between innovation and the $\mathrm{CE}$, we have invited a broad set of contributions. The chapters of the handbook are grouped into six parts that relate to different aspects of innovation for a CE. In the following paragraphs we summarize the parts of the handbook and how the chapters are related to key processes of managing CE innovations.

Part I provides an Introduction to innovation for a circular economy. Following the current chapter, Chapter 2 by Stahel offers a thought-provoking discussion on the types of innovation required to make progress in the transition to a $\mathrm{CE}$. As one of the pioneers of the $\mathrm{CE}$ concept, Stahel reflects on the need for radical innovation not only in the natural and material world, but even more important in the immaterial world. Stahel advocates for a refocus of CE research, and points at several promising avenues for developing circular sciences that would help us achieve a truly circular and sustainable economy.

Part II contains five chapters related to Firm-level enablers for circular economy innovation, and captures different CE strategies at the firm level and how these potentially enable the transition to a CE. In Chapter 3, Hermundsdottir et al. examine key differences in the sustainability strategies of manufacturing firms and their approach to address the environmental challenges of overuse of planetary resources and greenhouse gas emissions. Overall, they find that firms dealing with sustainability challenges devise effective strategies, which they expect will contribute to solving their industry's environmental challenges and provide firm-level competitiveness. Chapter 4 by Ingulfsvann further explores how five outdoor brands in Norway and Sweden are creating initiatives for retention and eco-innovation, which represent steps towards circular value chains. In Chapter 5, Oh et al. explore circular solutions in the fashion industry by focusing on how different forms of business activism and conceptions of organizational boundaries can shape firms' motives for embracing CE principles. They also discuss various 
enablers and barriers of CE, finding that $\mathrm{CE}$ improves environmental and social sustainability and creates opportunities for new profitable businesses in the fashion industry.

By adapting a case study of a radical innovation process for a renewable fuel technology, Chapter 6 by Kaipainen and Aarikka-Stenroos examines firm innovation strategies and processes for successful CE innovation. They map challenges and overcoming actions throughout the 25-year innovation process providing insights on how firms can successfully realize sustainable CE innovating processes. Adopting a multiple-case design of 12 SMEs in Cornwall, Chapter 7 by Ho et al. examines different forms of internal activism that trigger organizational change towards a $\mathrm{CE}$ and its relationship to four conceptions of $\mathrm{CE}$ business organizational boundaries (efficiency, power, competence, and identity). Their findings extend knowledge on organizational boundaries and highlights different organizational logics and distinct forms of CE internal activism.

Part III, Collaborative innovation for the circular economy captures the role of inter-firm collaboration and open innovation for CE, shared-value creation for parties involved, as well as circular supply chains and industrial symbiosis in regional circular ecosystems. Using data from the European Manufacturing Survey of Dutch manufacturing firms, Chapter 8 by Kok et al. investigates the relationship between firms' use of open innovation practices and the adoption of environmental process innovations. Their results show that firms who use more open innovation practices, more external information sources, or cooperate with international science-based partners also adopt more environmental process innovations. Chapter 9 by Tveit et al. investigates critical strategic aspects for achieving improved circular performance in the furniture supply chain, proposing a strategic framework for reverse logistics. Adapting a literature review on reverse logistics and an in-depth empirical case study of a furniture manufacturer, the chapter presents critical aspects of operations and business models that can enable or inhibit circularity as a value-creating system.

Further, in Chapter 10 Dreyer et al. explore what and how value is created by organizations in a Norwegian food bank and evaluate the impact of such banks on the sustaining circularity of the food system. Their results suggest that by implementing CE principles, food banks provide a fruitful basis for creating shared value and using economic gains to address environmental and social problems. Drawing on studies of 14 surplus heat exchanges in Norway, Johansen and Røyrvik in Chapter 11 show how valuation processes vary across localities, illustrating three different modes of valuating surplus heat: market commodity, a common good, or a gift between a company and the community. O'Shea et al. conducted a study on a regional CE ecosystem centred in the recycling of wastewater in Finland presented in Chapter 12. Based on 45 user-stakeholder interviews from ten different types of organisations within the ecosystem, their key findings highlight the importance of conscious, collaborative stakeholder support and ecosystem coordination for creating strong sustainable entrepreneurial ecosystems. Jakobsen and Steinmo in Chapter 13 identify drivers and barriers for industrial symbiosis between firms in an industrial park over the course of a decade, finding that developing a circular industry is a long-term process that requires open innovation efforts where academic institutions are essential in mobilizing firms towards circularity. Barriers for developing symbiosis in the park mainly relates to lack of access to risk capital to invest in research-based circular solutions. Finally, by adapting a game theory approach on a case from the fish farming industry, Chapter 14 by Aspelund et al. illustrates the challenges of simultaneous adoption of circular innovations, and discusses governmental interference to spur the adoption of circular practices. They show that the adoption of circular innovations requires coordinated and simultaneous adoption 
from multiple actors to succeed. As one actor's decision to adopt relies on other actors' actions, circular innovations and closing material loops rarely happen unless they are orchestrated.

Part IV, Types of circular economy innovations contains chapters that discuss CE innovations and provide examples from different industries and based on different business models. As current business model frameworks are hardly adjustable to the dynamic process of achieving a CE, Chapter 15 by Figueroa-Armijos proposes an emergent guiding framework, whose building blocks can be interchanged and adapted as progress is made. The framework is intended as a cumulative empirical tool for everyday use in the classroom and in practice to establish a CE foundational logic behind anchor purpose and value proposition. Bjørnstad and Grande in Chapter 16 also key into the debate of CE business models by examining opportunities and barriers for an entrepreneur's ability and incentives to innovate and develop circular and sustainable business models. They suggest that there exist both physical and systemic issues that pose fundamental challenges to the transition to a $\mathrm{CE}$ and identify key issues that society must address in the transition to a sustainable CE.

Further, based on an explorative multiple-case analysis strategy and mapping of 27 innovative $\mathrm{CE}$ offerings by various companies, Chapter 17 by Engez et al. uncovers several types of CE innovations - the sustainability issues they target, and pursued benefits. They develop a detailed categorization of CE innovation types: novel recycled materials (product innovations), sustainable production processes (process innovations), services for lengthening product lifecycles (service innovations), and business models for reusing and sharing products (business model innovations), that can guide managers in (re-)designing value propositions and business models in line with sustainable development goals. Chapter 18, by Wigger et al., offers a typology matrix consisting of seven types of resource loop innovations through an abductive study of innovation projects developed by Norwegian salmon farming firms. They propose that firms develop resource loop innovations of inbound, inhouse, and outbound resources, which minimize the use of unproductive resources of inbound and outbound resources and expand the range of inhouse resources. Through these resource loop innovations negative externalities are minimized and underutilized resources reused, which leads to increased resource circularity and a more sustainable industry.

Part V contains chapters related to Technology and digitalization for a circular economy. Based on action research conducted with over 40 organizations, Chapter 19 by Bocken et al. investigates experimentation practices companies adopt in the transition to a circular business model. As such, they provide an overview of business experimentation practices, possible tools, approaches and lessons learned; showing that significant planning and experimentation are needed to understand how to develop new business models that are not only 'circular', but also desirable for people, technically feasible, and financially viable. Chapter 20 by Rusthollkarhu et al. proposes four roles of digital technologies in CE customer value creation. The roles contribute to the $\mathrm{CE}$ literature by explaining how digital technologies enable companies and customers to create value based on CE principles. In practice, the roles help companies to understand the use of digital technologies in planning and executing CE business and help guiding innovation at the managerial level. Further, Chapter 21 by Huynh and Rasmussen explores the role of academic spin-offs and new ventures commercializing technologies by mapping the population of academic spin-offs established in Norway from 1999 to 2012, and identifies several digital innovations with potential CE impacts. The firms commercialized digital product and process innovations that were based on digital infrastructure technologies, which helped increase resource efficiency and optimize production performances. The authors 
also highlight that digital academic spin-offs play a role as technology suppliers and contribute to the CE by 'narrowing the loop' and reducing the consumption of resources and energy, as well as reducing waste emissions.

Chapter 22 by Modic et al. addresses methodological concerns about measuring and analysing data about technical innovations for a CE through patent data, and suggests a three phase 'budget' $\mathrm{Y}^{*}$-tag method to improve current indicators. In doing so, the authors outline procedures to combine 'Recycle' and other ' $R$ ' keyword searches of patent documents with validation of data from other sources, e.g., citations, inventor names, affiliations, locations and content. They also stress valid measurement for CE related innovation, if it is to be analysed with complementary data (e.g., research publications) with appropriate international comparisons to monitor the diffusion and impact of CE. The last chapter in this part, Chapter 23 by Fusillo et al. maps the development of CE technologies in European regions from 1980 to 2015 and identifies a core of CE technologies by using the official list of technological classes (CPC) and patent data from the OECD RegPat database. Their findings suggest that the CE knowledge space is a rapidly developing and dynamic technological field and that regional CE innovative efforts are quite heterogeneous, whereby regions tend to specialize in the generation of different kinds of CE technologies.

Finally, Part VI, Infrastructure enabling a circular economy is related to external factors and actors at both the business and system level that facilitate innovation activities for a CE. The contributions capture the role of venture capital and private equity funds, contractual agreements for research partnership, and public policies and procurement practices for innovation for a CE. Chapter 24 by Hegeman examines how venture capital and private equity funds innovate to invest in the CE market and the barriers they encounter. Using three pioneering fund managers as cases, Hegeman shows the need and ability for wide-ranging innovation to the fund model to overcome the issues created by the CE market's inefficiency, thinness, and unproven nature. Further, as many initiatives aimed at achieving $\mathrm{CE}$ are based on collaborations between industry and universities, in Chapter 25 Thue Lie et al. demonstrate a novel method for analysing the contractual agreements of research partnerships to investigate whether and to what extent the outcomes of research partnerships will be accessible. Hermann et al., in Chapter 26, further examine the alignment between top-down public policies to promote $\mathrm{CE}$ innovations and the interests of a range of stakeholders, including new ventures. Analysing 4,072 project applications to SkatteFUNN (a Norwegian tax deduction scheme aimed at supporting research and development), their findings indicate that the CE concept is much more complex than the few general principles highlighted in the literature. Finally, in Chapter 27 Dybtsyna et al. investigate the status of circular public procurement practices, showing that even in the case of a circularity conscious municipality, the environmental impact of public procurement still plays too insignificant a role for it to make a difference in the process of awarding contracts and steering the actors involved towards more circularity. They further highlight that circular public procurement practices need more specifically designed tender specifications and more susceptibility towards innovative procurement processes.

\section{CONCLUDING REMARKS}

Given the urgent need for a CE described initially in this chapter, the contributions of the handbook provide both hope and despair. Many of the chapters provide excellent examples 
of how CE principles are designed and implemented to make resource flows more circular. In combination the chapters clearly illustrate that conceptual thinking and experimentation with practical implementation of CE innovations take place at a growing rate and have become explicitly supported by actors across both the private and public sector. This offers hope that there exists an interest and capacity to develop circular solutions. However, the pace of this development is slow. Common to most of these examples are that the circular innovation only applies to a small part of a process, makes resource flows only marginally more circular and applies to only a few firms that are forerunners in the transition to a CE. Hence, these potentially novel innovations for a $\mathrm{CE}$ need to be implemented at a broad scale across firms, value chains, and industries in order to make a significant impact in terms of lower resource extraction, waste and pollution.

Another, but related, observation is that many of the examples of CE innovations presented in this handbook are relatively incremental, focusing on improving existing processes to reduce resource inputs or recycle to eliminate waste. These efforts are important, but the largest potential for achieving a full transition to a CE lies in making more radical changes. For instance, eliminating the need for products instead of lowering their resource inputs and designing for extended use instead of recycling holds a much larger potential for achieving a CE. However, such radical innovations typically require deeper changes across industry structures, consumer behaviour, and government regulations. Hence, the transition to a $\mathrm{CE}$ depends on innovation involving collaboration across sectors and industries, involving all actors in society.

These two observations call for a stronger role for innovation scholars in the CE transition. First, by addressing the need for innovations that optimize resource flows and make sure that CE principles are broadly adopted by all actors in the economy. Here, many of the chapters in this handbook offer inspiring examples for further development and implementation by other firms, industries, and public actors. Second, the need for more radical solutions to realize a CE calls for more coordinated and radical innovation efforts. This pushes the boundaries of innovation research which needs to better understand innovations involving collaborative efforts among a broad range of actors, involving entirely new business models, commercializing technologies and scientific discoveries, and focus on other goals than profitability.

\section{REFERENCES}

Almond, R. E. A., Grooten, M., \& Peterson, T. (2020). Living Planet Report 2020: Bending the Curve of Biodiversity Loss. Gland: WWF.

Barbieri, N., Marzucchi, A., \& Rizzo, U. (2020). Knowledge sources and impacts on subsequent inventions: Do green technologies differ from non-green ones? Research Policy, 49(2), 103901.

Bar-On, Y. M., Phillips, R., \& Milo, R. (2018). The biomass distribution on Earth. Proceedings of the National Academy of Sciences, 115(25), 6506-6511.

Crespi, F., Ghisetti, C., \& Quatraro, F. (2015). Environmental and innovation policies for the evolution of green technologies: A survey and a test. Eurasian Business Review, 5(2), 343-370.

De Marchi, V. (2012). Environmental innovation and R\&D cooperation: Empirical evidence from Spanish manufacturing firms. Research Policy, 41(3), 614-623.

De Wit, M., Hoogzaad, J., \& Von Daniels, C. (2020). The Circularity Gap Report 2020. Amsterdam: Ruparo.

Domenech, T., \& Bahn-Walkowiak, B. (2019). Transition towards a resource efficient circular economy in Europe: Policy lessons from the EU and the member states. Ecological Economics, 155, 7-19. 
Elhacham, E., Ben-Uri, L., Grozovski, J., Bar-On, Y. M., \& Milo, R. (2020). Global human-made mass exceeds all living biomass. Nature, 588, 442-444.

Ellen MacArthur Foundation [EMA] (2015). Growth Within: A Circular Economy Vision for a Competitive Europe. https://www.ellenmacarthurfoundation.org/assets/downloads/publications/ EllenMacArthurFoundation_Growth-Within_July15.pdf.

Ellen MacArthur Foundation [EMA] (2017). The New Plastics Economy: Rethinking the Future of Plastics and Catalysing Action. http://www.ellenmacarthurfoundation.org/publications/the-new -plastics-economy-rethinking-the-future-of-plastics-catalysing-action.

Esposito, M., Tse, T., \& Soufani, K. (2018). Introducing a circular economy: New thinking with new managerial and policy implications. California Management Review, 60(3), 5-19.

Fagerberg, J., Fosaas, M., \& Sapprasert, K. (2012). Innovation: Exploring the knowledge base. Research Policy, 41(7), 1132-1153.

Fleming, L., \& Sorenson, O. (2001). Technology as a complex adaptive system: Evidence from patent data. Research Policy, 30(7), 1019-1039.

Geissdoerfer, M., Pieroni, M. P., Pigosso, D. C., \& Soufani, K. (2020). Circular business models: A review. Journal of Cleaner Production, 227, 123741.

Geissdoerfer, M., Savaget, P., Bocken, N. M., \& Hultink, E. J. (2017). The circular economy: A new sustainability paradigm? Journal of Cleaner Production, 143, 757-768.

Ghisetti, C., Marzucchi, A., \& Montresor, S. (2015). The open eco-innovation mode: An empirical investigation of eleven European countries. Research Policy, 44(5), 1080-1093.

Henry, M., Bauwens, T., Hekkert, M., \& Kirchherr, J. (2020). A typology of circular start-ups: An analysis of 128 circular business models. Journal of Cleaner Production, 245, 118528.

Kemp, R., \& Pearson, P. (2007). Final Report MEI Project about Measuring Eco-Innovation. Maastricht: UM Merit.

Krafft, J., Quatraro, F., \& Saviotti, P. P. (2011). The knowledge-base evolution in biotechnology: A social network analysis. Economics of Innovation and New Technology, 20(5), 445-475.

Manninen, K., Koskela, S., Antikainen, R., Bocken, N., Dahlbo, H., \& Aminoff, A. (2018). Do circular economy business models capture intended environmental value propositions? Journal of Cleaner Production, 171, 413-422.

Merli, R., Preziosi, M., \& Acampora, A. (2018). How do scholars approach the circular economy? A systematic literature review. Journal of Cleaner Production, 178, 703-722.

Moreau, V., Sahakian, M., Van Griethuysen, P., \& Vuille, F. (2017). Coming full circle: Why social and institutional dimensions matter for the circular economy. Journal of Industrial Ecology, 21(3), 497-506.

Murray, A., Skene, K., \& Haynes, K. (2017). The circular economy: An interdisciplinary exploration of the concept and application in a global context. Journal of Business Ethics, 140(3), 369-380.

Nightingale, P. (1998). A cognitive model of innovation. Research Policy, 27(7), 689-709.

Prieto-Sandoval, V., Jaca, C., \& Ormazabal, M. (2018). Towards a consensus on the circular economy. Journal of Cleaner Production, 179, 605-615.

Rennings, K. (2000). Redefining innovation: Eco-innovation research and the contribution from ecological economics. Ecological Economics, 32(2), 319-332.

Sauvé, S., Bernard, S., \& Sloan, P. (2016). Environmental sciences, sustainable development and circular economy: Alternative concepts for trans-disciplinary research. Environmental Development, 17, 48-56.

Saviotti, P. P. (2007). On the dynamics of generation and utilisation of knowledge: The local character of knowledge. Structural Change and Economic Dynamics, 18(4), 387-408.

Schumpeter J. (1934). The Theory of Economic Development. Cambridge, MA: Harvard University Press.

Stahel, W. R. (2016). The circular economy. Nature, 531(7595), 435-438.

Steffen, W., Richardson, K., Rockström, J., Cornell, S. E., Fetzer, I., Bennett, E. M., ... \& Sörlin, S. (2015). Planetary boundaries: Guiding human development on a changing planet. Science, 347(6223), 1259855.

Weitzman, M. L. (1998). Recombinant growth. The Quarterly Journal of Economics, 113(2), 331-360.

Zeppini, P., \& van den Bergh, J. C. (2011). Competing recombinant technologies for environmental innovation: Extending Arthur's model of lock-in. Industry and Innovation, 18(3), 317-334. 